\title{
Fotografia no contestado: nova interpretação da rendição da família cabocla
}

Palavras-chave:
Fotografia
Guerra do Contestado
Caboclos

Keywords:

Photography

Guerra do Contestado

Caboclos

\author{
Gerson Witte* \\ Sônia Maria dos Santos Marques**
}

\begin{abstract}
Resumo: Este artigo faz a leitura de imagem dos aspectos formais e semióticos da fotografia de Claro Jansson e como ela foi interpretada na iconografia da Guerra do Contestado, representando o que seria uma rendição de uma família cabocla como resultado da estratégia de cerco aos redutos sertanejos, realizado pelo Exército Brasileiro. Compara-se a fotografia histórica com outras imagens do fotógrafo, com relatórios do Exército, livros e revistas que serviram como propaganda governamental para situar o local e data do evento com rendição do líder de reduto, Bonifácio José dos Santos e apresentando elementos culturais para demonstrar a necessidade de uma nova interpretação, relacionada com a execução de prisioneiros que aconteceu na cidade de Canoinhas, em Santa Catarina, no ano de 1915.
\end{abstract}

\begin{abstract}
The article makes na image reading of the formal and semiotic aspects of Claro Jansson's photography and how it was interpreted in the iconography of the Guerra do Contestado, representing what would be a surrender of a "cabocla" family as a result of the strategy of siege to the backcountry redoubts by the Brazilian Army. It is compared the historical photograph with other images of the photographer, with Army reports, books and magazines that served as governamental propaganda to situate the place and date of the event with the backcountry redoubt's leader surrender, Bonifácio José dos Santos's and presenting cultural elements to demonstrate the need for a new interpretation, related to the execution of prisoners that took place in the city of Canoinhas, Santa Catarina, in 1915.
\end{abstract}

Recebido em 18 de maio de 2017. Aprovado em 11 de setembro de 2017.

\section{Introdução}

Uma fotografia é icônica na Guerra do Contestado, sendo várias vezes utilizada em livros para representar a situação dos caboclos moradores dos redutos que sofreram no cerco realizado pelo Exército Brasileiro, que usou a estratégia da fome para combater os revoltosos do conflito armado que aconteceu entre os estados de Santa Catarina e Paraná, entre os anos de 1912 e 1916. Durante a pesquisa sobre esta imagem, foi possível creditar sua autoria ao fotógrafo de origem sueca, Claro Gustavo Jansson, estabelecido na cidade de Três Barras/SC, primeiro tenente da Guarda Nacional e contratado da Companhia Southern Brazil Lumber and Colonization. Suas fotografias foram utilizadas na época como propaganda de guerra pelo Exército Brasileiro, publicadas na revista semanal FonFon!, do Rio de Janeiro.

Muitas destas fotografias fazem parte atualmente do arquivo histórico do Exército Brasileiro; porém, sem registro de autoria. Mesmo existindo cópias das imagens em locais como o Arquivo Histórico de Caçador, foi graças aos esforços dos descendentes de Claro Jansson em preservar e divulgar seu acervo que foi possível atribuir sua autoria e permitiu a análise de outras de suas obras (MORETTI, 2015).

Com informações presentes nas memórias do comandante da Campanha do Contestado e do militar Demerval Peixoto, na publicação da

\footnotetext{
* Mestre em Educação pela Universidade Estadual do Oeste do Paraná (UNIOESTE). Professor de Artes do Instituto Federal de Santa Catarina (IFSC). Desenhista, ilustrador, artista gráfico e fotógrafo.

** Doutora em Educação pela Universidade Federal do Rio Grande do Sul (UFRGS). Professora Adjunta no Curso de Pedagogia da Universidade Estadual do Oeste do Paraná (UNIOESTE), Campus de Francisco Beltrão. Docente do Curso de Mestrado em Educação da UNIOESTE, Campus de Francisco Beltrão, linha de pesquisa: Cultura, Processos Educativos e Formação de Professores.
} 
revista Fon-Fon! e em outras imagens do fotógrafo Claro Jansson, foi também possível deduzir que a fotografia foi registrada entre os dias 14 e 20 de janeiro de 1915, no município de Canoinhas, o que levou ao questionamento de como a fotografia tem sido interpretada.

\section{A leitura da imagem e sua interpretação atual}

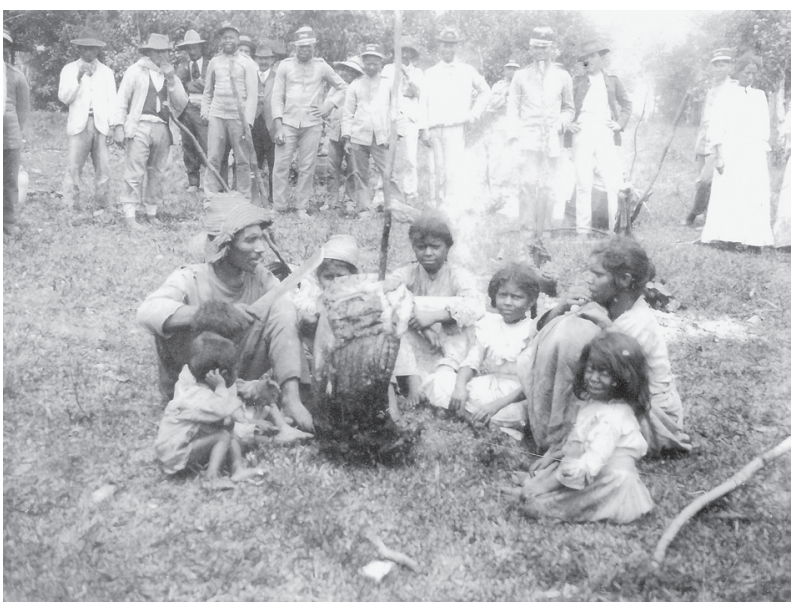

Figura 1 - Família cabocla no churrasco após a rendição

Autor: Claro Gustavo Jansson, 1915.

Fonte: Acervo da família Claro Jansson.

A imagem foi produzida utilizando a técnica de colódio seco em chapa de vidro, apresentando uma família com oito pessoas com a pele escura e vestindo farrapos, sentados no chão junto a uma costela de gado assada ao fogo. Atrás dessas pessoas, aparece a fogueira com outros espetos de madeira com pedaços de carne, mostrando onde foi feito o churrasco. No terceiro plano, identificam-se 17 homens e uma mulher, dentre os quais sete apresentam identificação com o uniforme do exército brasileiro. O local aparenta ser um campo gramado com vegetação abundante e árvores no fundo.

Uma interpretação sobre o que esta imagem representaria seria a seguinte:

A fotografia é reveladora do contexto histórico final do movimento do Contestado, quando os sertanejos, diante da situação em que se encontravam de penúria, foram rendendo-se às forças legais. Nela, o fotógrafo procurou colocar em destaque os sertanejos rebelados, pois se encontra bem à frente dos demais, um homem acompanhado de seis crianças, estrategicamente dispostas. Pés descalços, roupas maltrapilhas, com a pele queimada do sol, empoeirados, sugerem, pela imagem, que há dias perambulavam pelas matas em busca de um lugar com segurança e alimentação. (TONON; LIMA, 2015, p. 203).

A imagem apareceu em outras obras sobre o Contestado. No livro Uma Breve História do Contestado, o historiador Nilson Thomé (2005, p.35) publicou a referida fotografia com a seguinte legenda: "Flagrante de uma família de caboclos rebeldes, quando se rendia às forças militares da Coluna Leste. Milhares de sertanejos, cercados pelo Exército, vencidos pela fome e pelo tifo, entregamse para escapar da morte".

A fotografia foi também situada na cidade de Canoinhas, no ano de 1915, onde o Exército Brasileiro acampou durante a Campanha do Contestado. Para Tonon e Lima (2015, p. 204), a realização da fotografia teria a intencionalidade de mostrar os sertanejos e seus familiares sendo alimentados após a rendição, apresentando uma visualidade plástica que revelaria o bom tratamento concedido aos sertanejos, presentes nos discursos dos militares.

\section{A descoberta do contexto}

A chave para contextualizar a imagem da rendição da família cabocla foi outra fotografia de Claro Jansson. Ao fazer uma leitura mais atenta do registro da rendição ao Exército Brasileiro do líder sertanejo Bonifácio José dos Santos, conhecido como Bonifácio Papudo, percebi no segundo plano e no canto direito a presença do mesmo homem da família sertaneja referente à Figura 1, tendo também à sua frente uma costela de gado, colocando os dois acontecimentos em sequência. A importância desta descoberta era a possibilidade de situar o evento em um lugar no espaço geográfico e no tempo, porque a capitulação do líder sertanejo foi registrada nas memórias do general Setembrino de Carvalho. 


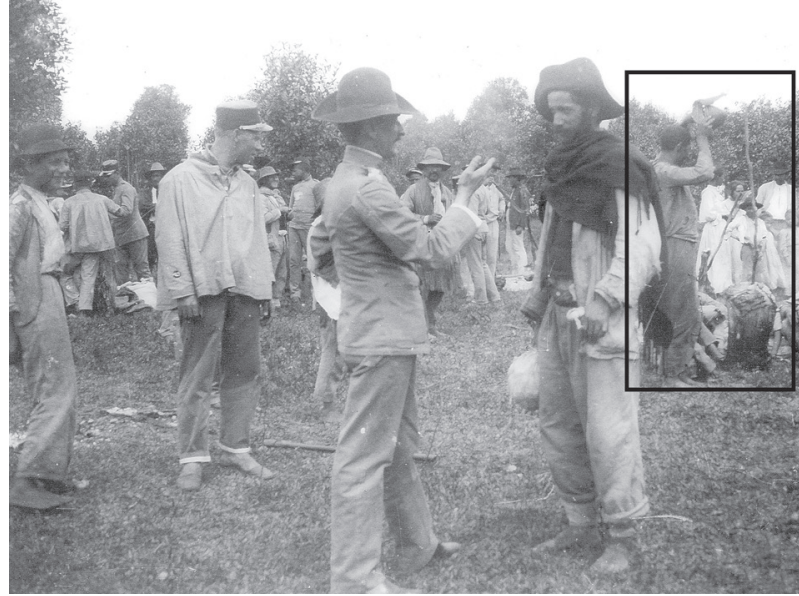

Figura 2 - A capitulação do líder sertanejo Bonifácio Papudo, com destaque para a família cabocla ao fundo. Autor: Claro Gustavo Jansson.

Fonte: Valentini et al. $(2015$, p. 222).

A descoberta levou a uma análise aprofundada de outras fotografias de Claro Jansson, onde foi identificada a mesma família em outros retratos, e, em uma delas, aparecia Henrique Wolland, o Alemãozinho, o primeiro líder dos sertanejos a se render para as tropas governamentais, fato que aconteceu poucos dias antes de 8 de janeiro de 1915, data da destruição do reduto de Antônio Tavares. No seu livro de memórias (SETEMBRINO DE CARVALHO, 1950), o então general narrou a destruição deste importante centro de resistência sertaneja, que ficava nas proximidades da cidade, que em 10 de janeiro de 1915 despachou as ordens do dia em Iracema/PR e sua partida para a cidade de Rio Negro, no dia seguinte. Demerval Peixoto, no seu livro Campanha do Contestado - Episódios e Impressões (1916), informou que Setembrino de Carvalho chegou dia 12 de janeiro de 1915.

As fotos foram produzidas pela técnica do colódio seco em chapas de vidro, reveladas, selecionadas, copiadas em papel e enviadas para o Rio de Janeiro a tempo de serem publicadas no dia 6 de fevereiro de 1915 na revista de variedades da capital federal, Fon-Fon!, utilizada pelo exército como propaganda durante a Campanha do Contestado.

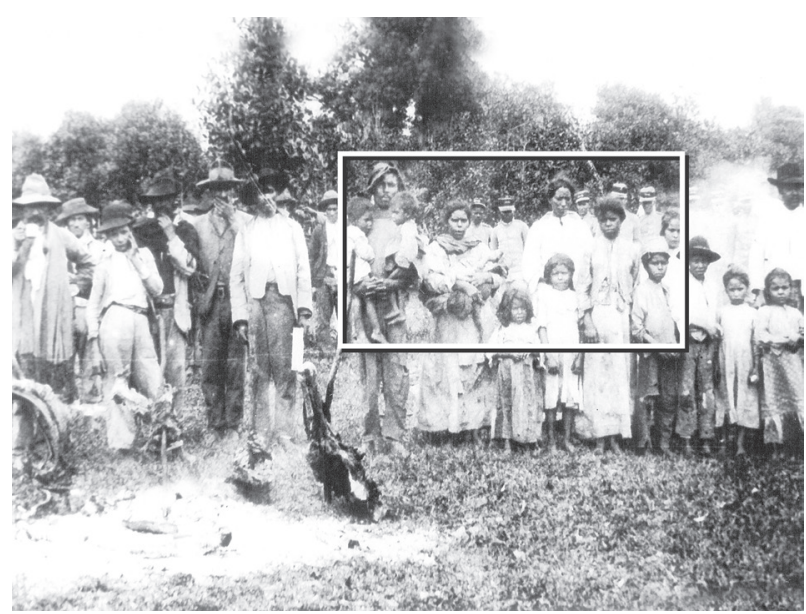

Figura 3 - Rendição de sertanejos, com destaque para a família

Autor: Claro Gustavo Jansson.

Fonte: Acervo da família Claro Jansson.

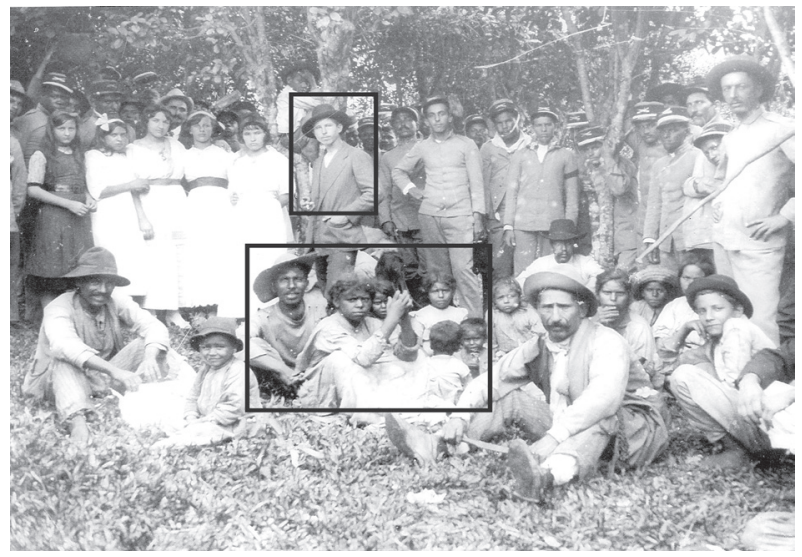

Figura 4 - Rendição de sertanejos com o exército, com destaques na família e em Henrique Wolland Autor: Claro Gustavo Jansson.

Fonte: Acervo da família Claro Jansson.

A análise das fotos e das legendas na publicação permitiu a reconstituição dos acontecimentos daquele dia 12 de janeiro de 1915: após passar suas tropas em revista, foi celebrada uma missa campal pelo frei Rogério de Neuhaus (PEIXOTO, 1920), seguido de almoço festivo com churrasco. O importante, para a interpretação da fotografia da rendição da família cabocla é a última imagem impressa na revista, que traz a seguinte legenda: "8. Grupo de fanáticos churrasqueando depois da missa campal + Chefe fanático alemãozinho". A reprodução digital da revista apresenta baixa qualidade, mas cruzando referências, foi possível localizar a imagem na exposição virtual do Arquivo Histórico do Exército. 


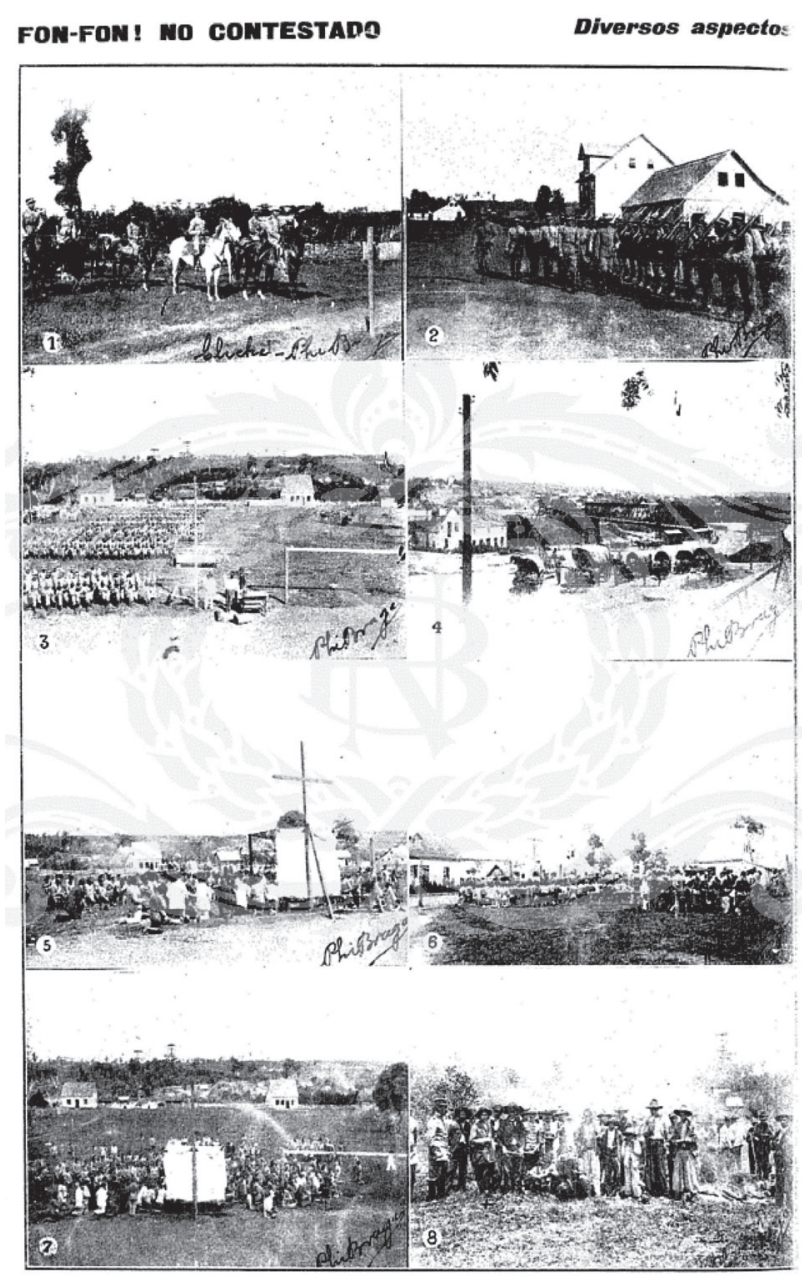

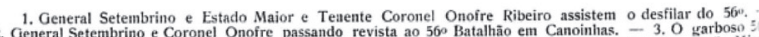

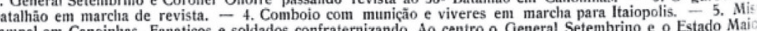
carnpal em Canoinhias. Fanaticos e soldados confraternizando. Ao centro o General Setembrino e o Estado.
-6 . Outro aspecto da missa. - 7. Outro aspecto da missa. -8 . Grupo de fanaticos churrasqueando depois -6 . Outro aspecto da missa -7 . Outro as art
missa campal. - Chefe fanatico Alemăosinho.

Figura 5 - Fac-símile de página da "Revista Fon-Fon! de 6 de fevereiro de 1915

Fonte: Revista Fon-Fon! (1915).

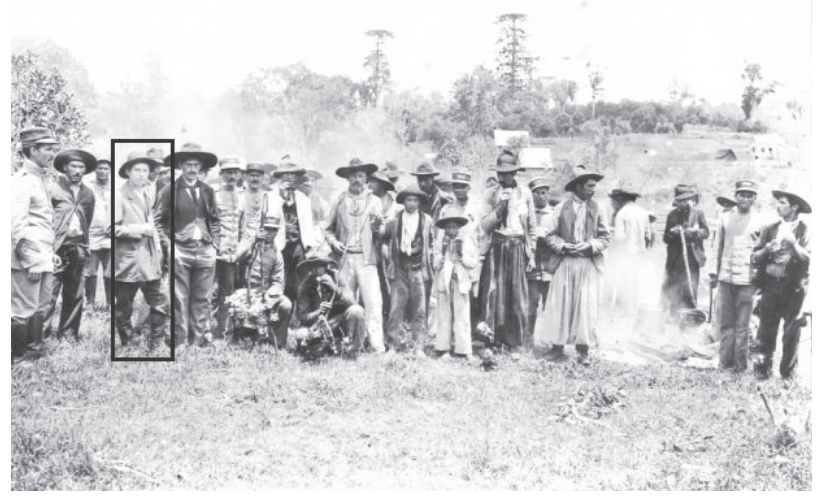

Figura 6 - Churrasco após a missa campal, com destaque em Henrique Wolland

Autor: Claro Gustavo Jansson.

Fonte: Arquivo Histórico do Exército.
A fotografia com Bonifácio Papudo não aconteceu naquele dia, mas pelo cruzamento de informações, provavelmente ocorreu entre os dias 14 e 20 de janeiro de 1915, pelo menos dois dias após a chegada do general à cidade e pelo menos dois dias antes de sua partida. Se a fotografia foi realizada em frente do piquete, como eram conhecidos os grupos armados na região, provavelmente a família cabocla fazia parte dos liderados de Bonifácio Papudo, que confiou nas garantias oferecidas pelo exército brasileiro para cessar as hostilidades. Esta nova rendição também foi comemorada com missa campal e almoço festivo com churrasco, conforme está descrito nas memórias de Setembrino de Carvalho.

\begin{abstract}
A incessante atividade do comandante desta linha e do seu chefe de Polícia Militar devemos ter recebido vários chefes bandoleiros com os quais em uma reunião, que merece ser mencionada, porque era um general do Exército que parlamentava com celerados da pior espécie. Consegui inspirarlhes confiança, de modo que durante minha permanência em Canoinhas, diariamente presenciávamos a entrada de grupos que vinham entregar-se. Do meu quartel general mandei fotografar o chefe Bonifácio Papudo à frente de seu piquete, quando atravessava a praça da localidade em direção à Chefatura de Polícia. (CARVALHO, 1950, p. 154).
\end{abstract}

Mesmo estando em Canoinhas, o envio do tenente Castello Branco para esta tarefa demonstra que o general considerava indigno legitimar a liderança de alguém que considerava um "bandido que mais jus tivesse feito, não às honras de um fuzilamento, mas à forca" (SETEMBRINO DE CARVALHO,1950, p.170). O fotógrafo registrou várias outras imagens, sempre com a intenção de apresentar os revoltosos rendidos ao poder do exército. Algumas destas fotografias foram reunidas por Setembrino de Carvalho como um álbum de guerra, sendo hoje parte do Arquivo Histórico do Exército; porém, não foram publicadas na revista Fon-Fon! na edição de 6 de fevereiro nem nas publicações posteriores, que passaram a mostrar os equipamentos, as manobras, a organização 
do Exército na região e a visita do general a uma comunidade de colonizadores europeus.

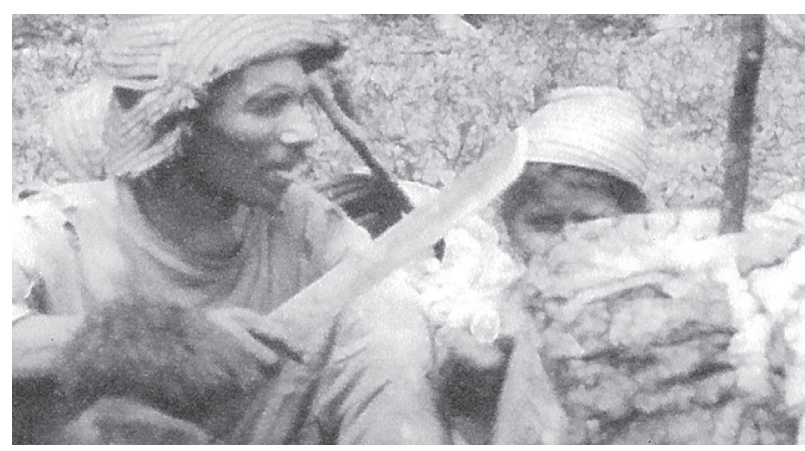

Figura 7 - Detalhe do facão na fotografia de rendição da família cabocla

Autor: Claro Gustavo Jansson.

Fonte: Acervo da família Claro Jansson.

A fotografia da rendição da família cabocla não foi utilizada como peça de propaganda do exército e não fizeram parte do arquivo do general Setembrino de Carvalho, conclui-se que a imagem não foi adquirida pelo governo brasileiro, provavelmente porque a narrativa não representava seus interesses. Outra incongruência na interpretação de que a rendição da família de caboclos foi motivada pelo desespero e pela fome não se sustenta, uma vez que o suposto prisioneiro permaneceu de posse de uma arma, o facão, o que corrobora a interpretação de capitulação pacífica.

Um elemento da cultura cabocla auxilia em uma nova interpretação para a fotografia. Em 2014, realizei um levantamento fotográfico dos principais locais relacionados ao Contestado e visitei o importante centro de resistência dos sertanejos na Guerra do Contestado, o reduto de Santa Maria, no município de Timbó Grande, localizado no interior de Santa Catarina. Era uma manhã de domingo e por ser dia de festa religiosa, o único local existente para almoço naquele dia era no pavilhão da igreja católica.

O churrasco com salada, pão, maionese foi uma experiência perfeita no contexto de uma pesquisa cultural sobre a região do Contestado. Ao sair, deparei-me com três famílias que também participavam do almoço festivo, mas sob a sombra das árvores. Nela, dois adultos e uma criança estão ao lado de um espeto com churrasco, sentados no chão, com o homem cortando pedaços de carne com sua faca e distribuindo aos demais, demonstrando ser este um costume local para se servir o churrasco, com as outras duas famílias repetindo o mesmo gesto.

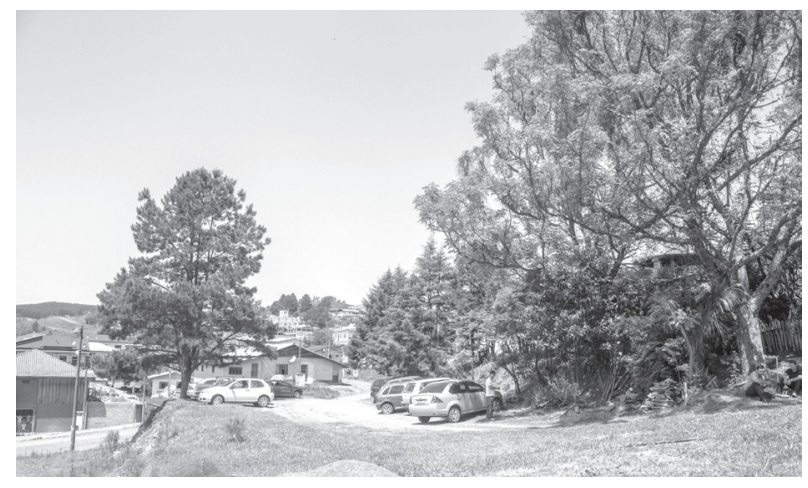

Figura 8 - Terreno ao lado da Igreja Católica de Timbó Grande/SC, local do último reduto Autor: Gerson Witte. Fonte: Arquivo Pessoal.

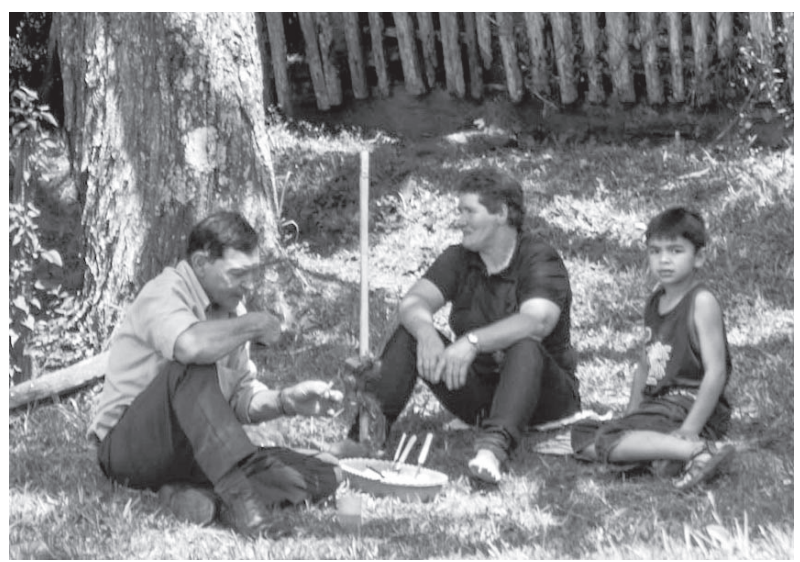

Figura 9 - Família almoçando ao lado da Igreja Católica de Timbó Grande/SC

Autor: Gerson Witte.

Fonte: Arquivo Pessoal.

A igreja foi construída no local onde outro líder dos sertanejos do Contestado, Adeodato, fez a última tentativa de reagrupar as forças em um reduto, que foi destruído pelos capangas dos fazendeiros. Registrei o lugar e uma das famílias, motivado pelo visual bucólico daquele singelo almoço de domingo. Porém, ao comparar com a imagem da rendição da família cabocla, a semelhança entre este meu registro e a fotografia de Claro Jansson se tornou flagrante e expondo o motivo daquelas pessoas se alimentarem no chão: simplesmente era um costume dos moradores sertanejos da região. 
Imaginando aquele dia de janeiro de 1915, com o fogo à lenha sendo feito no chão para assar peças de carne colocadas ao seu redor em espetos de madeira, em um local sem a infraestrutura necessária, como servir o almoço para o grande afluxo de pessoas que pertenciam ao piquete de Bonifácio Papudo, além das tropas do exército e dos moradores das redondezas que foram participar da missa campal? A fotografia representa como aquelas pessoas participavam do almoço, servindo a carne à sombra das árvores, sentados no gramado. Os detalhes selecionados nas duas fotografias mostram uma importante relação entre duas crianças do Contestado, compartilhando um almoço em família da mesma forma, mesmo separadas por um século.

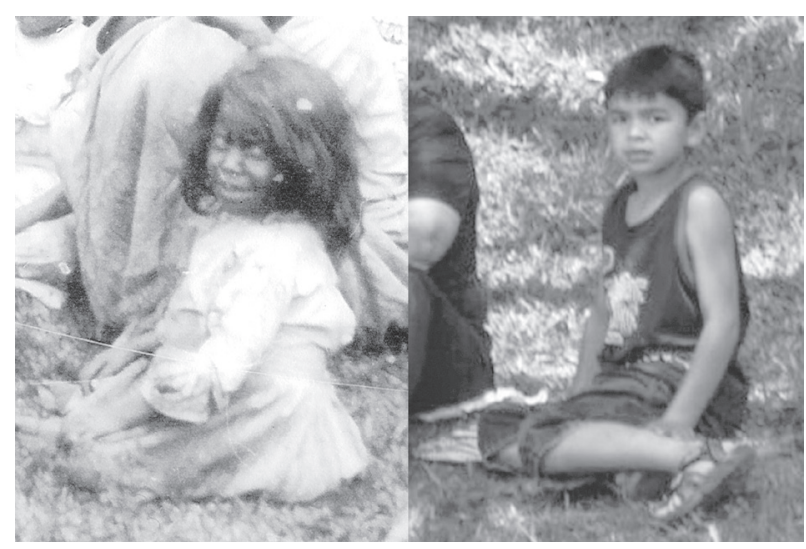

Figura 10 - Detalhes comparativos das Figuras 1 e 9, destacando as crianças na mesma pose, com a diferença de um século

Na nova interpretação sugerida, não existiu desespero ou humilhação no fato de estarem comendo no chão. Foi Claro Jansson, um artista contratado por uma companhia estrangeira e ordenado por um oficial do exército para registrar a rendição de um líder de piquete, que teve a sensibilidade de perceber aquela família de caboclos que foram recebidos com festa. Estes moradores do Contestado, na verdade,mostraramse orgulhosos, divertindo-se e conscientes da honra que recebiam ao terem seu retrato realizado naquele momento. Contudo, para entender assim a imagem, é necessário desconstruir a representação dos caboclos como fanáticos ignorantes e os colocarmos como pessoas que sabiam das inovações tecnológicas e aproveitaram a rara oportunidade de registrar sua família. Seria a exibição do orgulho do casal por seus filhos em um dia de festa religiosa, contrastando com os preconceitos pelos quais caboclos que lutaram na Guerra do Contestado sofreram do governo e da imprensa na época, o que levou à interpretação de que a cena apenas poderia representar sua humilhação.

O ideal seria terminar aqui a interpretação da fotografia, que representaria um momento de alegria em família em meio a uma violenta revolta armada. Mas a continuidade das pesquisas sugere que a fotografia da rendição da família cabocla nunca foi utilizada pelo Exército Brasileiro, por estar ligada a outro acontecimento da Guerra do Contestado: a degola de prisioneiros.

\section{O massacre dos prisioneiros em janeiro de 1915}

A fotografia pode estar relacionada a um acontecimento da Guerra do Contestado que manchou a carreira do general Setembrino, no parágrafo em que narra como ordenou a fotografia da rendição de Bonifácio Papudo, ele conclui com a seguinte e intrigante frase: "Era deste modo que eram ordenados os degolamentos dos pobres sertanejos!" (SETEMBRINO DE CARVALHO, 1950 , p. 154). Para compreender como aquelas fotografias estão ligadas a execuções sumárias, cito uma publicação de 18 de maio de 1915 do jornal catarinense $O$ Estado:

Da cadeia de Canoinhas eram retirados
diariamente levas de desgraçados que se
tinham apresentado voluntariamente, e
entregues a Pedro Ruivo, um celerado
vaqueano promovido a herói. Pedro
Ruivo conduzia as vítimas para fora da
vila e, na primeira curva do caminho,
degolava-as. Os cadáveres ficavam
insepultos. Os porcos e os corvos
tinham fome. (O DISCURSO..., p. 1,
1915).

Os capangas dos coronéis da região eram conhecidos como vaqueanos e no texto do periódico, o responsável pelas execuções Pedro Leão de Carvalho, vulgo Pedro Ruivo, teria executado mais 
de 100 prisioneiros a mando do Coronel da Guarda Nacional, Onofre Ribeiro. O jornalista exaltou a bravura dos combatentes; todavia, afirmou que não se podia dizer o mesmo de todos, porque "houve incêndios demais e degolamentos revoltantes", além de estupros, assassinatos de mulheres e crianças, roubos e incêndios, visto que "certos vaqueanos eram verdadeiros monstros" (O DISCURSO..., 1915, p. 1).

Sobre o mesmo acontecimento, a Gazetta do Commercio, da cidade de Joinville/SC,publicou uma nota sobre o degolamento de 154 fanáticos nas margens do rio Iguaçu, nas localidades de Putinga, Lagoa, Barra-Feia, Santa Leocádia e Vallões e “[...] diz nosso informante que é uma lástima, ver-se as famílias que ficaram sem seus chefes e sem pais, e eram obrigados a assistir a execução de seus parentes! Que ato revoltante de degolar cidadões [sic] sem sentença" (NOTÍCIAS...,1915, p. 2).

Podem-se fazer várias especulações para explicar as motivações para a execuções naquele momento da Guerra do Contestado. Por exemplo, Antônio Tavares Junior, em carta ao Major Taurino de Rezende e citado por Peixoto (1920), relatou a necessidade de abater cinco reses por dia, além de adquirir 60 sacos de farinha de mandioca e 20 sacos de sal de cozinha para manter o seu piquete, e, como chegaram a receber 3.000 refugiados nos acampamentos, isso pode ter servido para conter os custos de alimentar a todos. Outra suposição é que os coronéis Fabrício Vieira e Onofre Ribeiro realizaram suas vinganças particulares a desafetos. Poderia existir também o receio de que, entre os refugiados, existissem agentes do reduto infiltrados, prontos para atacar a retaguarda do exército no momento do avanço das tropas. Por fim, seria um resquício dos costumes da Revolta Federalista, onde este tipo de execução foi o principal tratamento dispensado aos prisioneiros.

Demerval Peixoto escreveu um parágrafo que pode estar relacionado ao ocorrido:

O General, entretanto, não deu-se por achado continuando carinhosamente a receber aqueles verdadeiros despojos humanos, desgraçados e entesinhos inocentes, muitos dos quais despidosos corpinhos tiritantes, outros alimentando-se unicamente com o sugar das mamas emurchecidas das pobres mães desgrenhadas e infelizes. Pois bem. Afastando dos elementos perdidos, os míseros inculpados da desgraça em que estavam procurando selecionar os arrependidos dos malfeitores contumazes, o General preparava-se para agir energicamente contra o restante da grei insubmissa. (PEIXOTO, 1920, p. 483). ${ }^{1}$

O jornal da capital paranaense A República transcreveu em junho de 1916 a sessão da Câmara dos Deputados do dia 15 de maio de 1916, onde Maurício de Lacerda, representante do Rio de Janeiro, faz a requisição de investigação sobre o caso de degolas e fuzilamentos e, em especial, que se investigasse a figura do coronel Fabrício Vieira, contratado pelo governo para auxiliar as forças militares. João Pernetta, representante do Paraná, defendeu as atitudes das forças militares e a do General Setembrino de Carvalho. Maurício de Lacerda insistiu diversas vezes em perguntar se houve ou não degolamentos no Paraná, ao que o deputado paranaense defende serem apenas "calúnias e difamação contra o exército". Mesmo com o deputado carioca declarando não estar acusando o general por nenhum crime, que teria sido cometido pelo coronel, o deputado Pernetta apenas tergiversou em suas respostas (DEFEZA..., 1916).

A degola dos prisioneiros manchou a carreira do general a ponto de, 35 anos depois do fim da guerra, ainda precisar se apresentar como inocente sobre as degolas e negar sempre que ordenou a execução de prisioneiros no seu livro de memórias. Nos documentos pesquisados, não existe nenhum registro de ação direta de Setembrino de Carvalho ordenando as execuções; contudo, também inexiste qualquer ação para impedir ou punir os responsáveis, porque o acusado de ser o principal executor das degolas, o vaqueano Pedro Ruivo, continuou como chefe de um piquete de vaqueanos, atuando até o final da guerra junto à Terceira Companhia do $56^{\circ}$. Batalhão do Exército, sob as ordens do Capitão Tertuliano Potyguara. 
A fotografia da rendição da família cabocla pode nunca ter sido utilizada como propaganda por estar diretamente relacionada a este episódio e ter sido também executada sumariamente, após ter se rendido, confiando nas promessas do governo brasileiro. Pode ser o último registro daquele homem, de sua esposa e de seus filhos antes de terem os pescoços atravessados por uma faca e deixados insepultos para apodrecerem na curva da estrada.

\section{Considerações finais}

A Figura 11 é uma fotografia de Claro Jansson identificada por Salomão (2012) como sendo do piquete Pedro Ruivo, enquanto Jansson estava em Três Barras/SC. O autor comenta que foi utilizada por muitos anos em diversas publicações como sendo uma imagem dos "fanáticos" do Contestado e que, sendo intencional ou não, esta troca gera uma imagem dos sertanejos rebelados que coaduna com os interesses do Exército ao gerar a representação de que estavam lutando contra tropas bem armadas e organizadas, em vez de um exército lutando contra famílias de maltrapilhos, como a da Figura 1

Aqueles que fizeram o ato de crueldade contra os sertanejos revoltosos se tornaram a representação nas obras sobre a Guerra do Contestado, resultado da ignorância quanto ao fato de os caboclos terem lutado nos dois lados do conflito. Enquanto os espoliados se revoltaram contra a opressão dos coronéis e da chegada da estrada de ferro, apegando-se à fé no monge João Maria, do outro lado, os igualmente pobres caboclos ligados aos coronéis arriscaram a vida em combates em meio à floresta, em troco do soldo pago pelo exército e pelo butim de guerra, como apresenta Salomão (2012).Foi um povo que combateu a si mesmo, todos ligados pela pobreza, pelo preconceito e descaso a que estavam submetidos os moradores do sertão meridional brasileiro no início do século XX.

Sobre a fotografia da família cabocla e a maneira que foi interpretada, percebe-se a necessidade do aprofundamento dos estudos sobre a cultura cabocla da região do Contestado, para compreender como os costumes influenciaram a construção da identidade destas pessoas. O acervo fotográfico de Claro Gustavo Jansson também deveria ser analisado como fonte histórica da Guerra do Contestado e não servir apenas como ilustração de textos,muitas vezes descontextualizados e representando estereótipos.

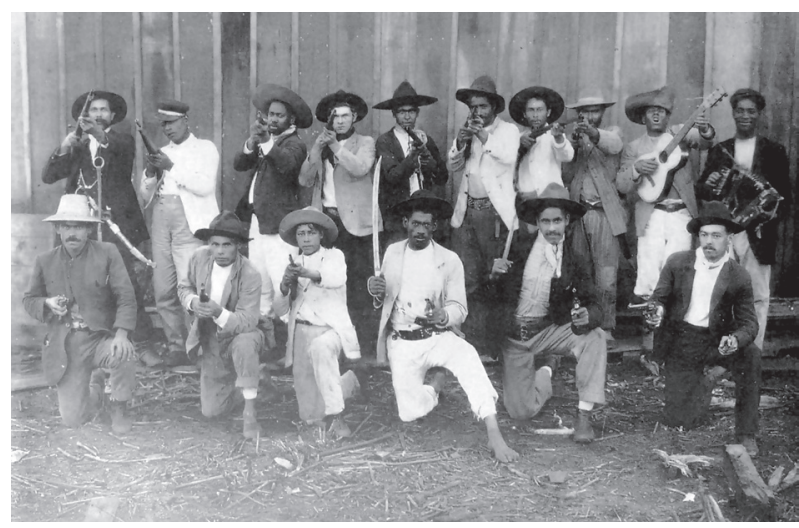

Figura 11 - Piquete de Pedro Ruivo, em Três Barras/SC Autor: Claro Gustavo Jansson.

Fonte: Acervo da família Jansson.

Inspirado em um trecho publicado no jornal $O$ Estado, em que o jornalista escreveu que "mais cedo do que se pensa, a História esclarecerá este caso doloroso de fanáticos" (O DISCURSO ..., 1915, p. 1), sugiro, para futuras utilizações da fotografia da rendição da família cabocla, que a legenda a ser utilizada para descrevê-la seja: "durante a Guerra do Contestado, caboclos foram degolados após terem se rendido pacificamente ao Exército Brasileiro, supostamente pelo vaqueano Pedro Ruivo, a mando dos coronéis Onofre Ribeiro e Fabrício Oliveira. Canoinhas, janeiro de 1915”. Os nomes dos algozes deveriam ser lembrados por seus atos contra a humanidade, para que passados mais de 100 anos destas mortes, o caso não permaneça dolorosamente esquecido pela história.

\section{Nota}

$1 \mathrm{O}$ trecho foi transcrito com a gramática da época.

\section{Referências}

ACERVO DA FAMÍLIA CLARO JANSSON. Fotografias de Claro Gustavo Jansson. 
DEFEZA do General Setembrino de Carvalho. A República, Curitiba, ano 31, n. 126, 1 jun.1916, p. 1.

EXPOSIÇÃO VIRTUAL DO EXÉRCITO SOBRE A CAMPANHA DO CONTESTADO. Disponível em:<http://www.ahex.ensino.eb.br/index.php/pt/ contestado $>$. Acesso em: 5 ago. 2016.

FON-FON! no Contestado - Diversos Aspectos. Fon-Fon! Ano IX, n. 6. Página 22. 06 de fevereiro de 1915. Rio do Janeiro, RJ.

MORETTI, D. J. Prefácio. In: VALENTINI, D. J.; WITTE, G.; CARBONERA, M.; SALINI, A. M.; ONGHERO, A. L. (Orgs.). Revelando o Contestado: as fotografias na história do centenário da guerra Chapecó: Argos, 2015. pp. 7-10.

NOTÍCIAS Locaes. Gazetta do Commercio, Joinville, ano 2, n. 19, 6 mar. 1915, p. 2.

O DISCURSO do General. O Estado, Florianópolis, ano 1, n.4, 18 maio 1915, p. 1.

PEIXOTO, D. Campanha do Contestado Episódios e Impressões. Rio de Janeiro:1920.

SALOMÃO, E. R. A Imagem da Capa. Revista de História da Biblioteca Nacional. Rio de Janeiro: Sociedade dos amigos da Biblioteca Nacional, ano 7, n. 85, p. 4, out. 2012.
SETEMBRINO DE CARVALHO, F. Relatório Apresentado ao General de Divisão José Caetano de Faria, ministro da Guerra - 1915. Imprensa Militar. Rio de Janeiro, 1916. Memórias - Dados para a História do Brasil. Rio de Janeiro, 1950.

THOMÉ, N. Breve História da Guerra do Contestado. 1. ed. Caçador: Nilson Thomé, 2005. v. 1 .

TONON, E.; LIMA, S. R. Contestado e o impacto na modernidade: da hermenêutica fotográfica. In: VALENTINI, D. J.; ROSA, R. (Org.). Contestado: fronteiras, colonização e conflitos (1912-2014). 1. ed. Porto Alegre: Letra \& Vida, 2015. p. 191-204.

VALENTINI, D. J.; WITTE, G.; CARBONERA, M.; SAliNI, A. M.; ONGHERO, A. L. (Orgs.). Revelando o Contestado: as fotografias na história do centenário da guerra Chapecó: Argos, 2015.

.; BORELLI, R. Doze pares de cenas da História do Contestado: arte e cultura na representação da fúria cabocla. Curitiba: Orion, 2009.

WITTE, G. Acervo pessoal de fotografias. 